\title{
Post-Classical Greek from a Scribal Perspective.
}

\section{Variation and Change in Contemporary Orthographic Norms in Documentary Papyri}

\author{
Joanne Vera Stolk \\ University of Oslo, Dept. of Philosophy, Classics, History of Art and Ideas \\ Ghent University, Dept. of Linguistics \\ joanne.stolk@ugent.be
}

Received April 2019| Accepted July 2019

\begin{abstract}
Spelling deviations are often considered to be the result of random variation or plain mistakes by the scribes. Based on the examples in this paper, I argue that some of the apparent deviations may actually be in accordance with contemporary norms. Close study of the spelling of five lexemes in the corpus of documentary papyri shows that the orthographic conventions at the time may have been different than suggested by contemporary grammarians and modern editors.
\end{abstract}

\section{Keywords}

post-classical Greek - orthography - documentary papyri - variation and change - scribes grammarians

\section{Introduction}

Changes from classical to post-classical Greek can be found at almost every level of the language (e.g. phonology, morphology, syntax and lexicon), marking the appearance of some 
of the characteristic traits of Modern Greek. ${ }^{1}$ Post-classical Greek orthography, however, is generally assumed to follow a classical Attic model with a few exceptions, mostly of Ionic origin, such as the preference for $-\sigma \sigma-$ and $-\rho \sigma$ - instead of $-\tau \tau$ - and $-\rho \rho-$ and the simplification of the cluster $-\gamma \nu$ - to $-v-{ }^{2}$ Although Greek spelling has remained conservative until the modern day, it is hard to believe that post-classical orthography really remained without any changes - not even temporary ones - in scribal norms and practices throughout the Hellenistic, Roman and Byzantine periods. Apart from these few well-known changes, our knowledge of post-classical orthography is limited and primarily based on the transmission of literature rather than on actual examples of writing at the time. Literary sources, often transmitted over many centuries, may not be the easiest place to identify orthographic innovation. Documentary papyri, on the other hand, provide an opportunity to challenge our ideas about the standards of post-classical Greek orthography and they can be compared to the views of (contemporary) grammarians and lexicographers.

\section{Greek orthography}

Spelling variation is commonly found in documentary papyri as a result of phonological developments, as Gignac explains:

... spelling mistakes in the papyri are similarly instructive for the phonology of postclassical Greek, in which there was a disparity between spelling and pronunciation analogous to that in present-day English. The fixed conventional spelling system of Greek progressively failed to reflect a radically changing pronunciation, so that by

\footnotetext{
${ }^{1}$ See e.g. Horrocks 2010, 88-188.

${ }^{2}$ See Horrocks 2010, 82.
} 
Roman and Byzantine times many sounds had several possible representations in writing. ${ }^{3}$

The phonological changes and the emergence of "several possible representations in writing" during the Hellenistic period presented a challenging phase in the process of codification of post-classical Greek orthography. I take the term orthography to refer to "a more or less binding norm that can lead to criticism in case of non-compliance" which is established by "the practices of a community of writers within a certain period". ${ }^{4}$ As Gignac shows, many scholars tend to speak about orthographic variation in papyri in terms of "spelling mistakes", because they assume that the Greek spelling system consisted of the largely 'fixed' and 'conventional' set of orthographic rules known to us.

The notion of orthography as 'the correct spelling of a word and the account of its correctness', as defined by Trypho, was already established by the Hellenistic grammarians and codified by the grammarian Aelius Herodian in the second century CE. ${ }^{5}$ A continuous tradition of reproduction and adaptation preserves major parts of these earlier works on orthography throughout the Byzantine period and Middle Ages. The grammarians used the following four criteria for determining the correct spelling, originally used for textual criticism: analogy ( $\alpha \dot{v} \alpha \lambda \mathrm{o} \gamma \mathbf{i} \alpha$ ), namely the formulation of general propositions based on

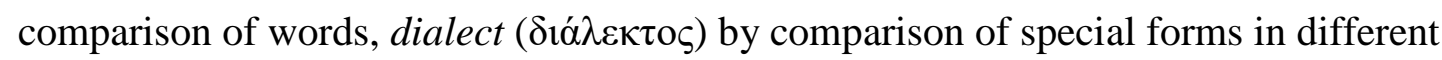

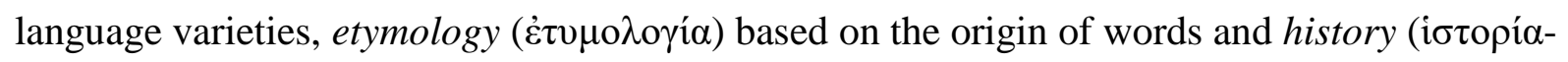
$\pi \alpha \rho \alpha ́ \delta o \sigma ı \varsigma)$, which informs us about how the word is used in the literary textual tradition. ${ }^{6}$

\footnotetext{
${ }^{3}$ Gignac 1976, 58.

${ }^{4}$ See Rutkowska and Rössler 2012, 214.

${ }^{5}$ See Valente 2015.

${ }^{6}$ See Siebenborn 1976, 56-163; Valente 2015, 970-975.
} 
Siebenborn suggests that a fifth criterion, the use of the word in contemporary language ( $\sigma v v \eta \dot{\theta} \theta \varepsilon 1 \alpha$ ), is not generally applied to orthography by the Greek grammarians, because it would not be helpful to establish the correct spelling of sounds that were identical in contemporary pronunciation. $^{7}$

This leads us to the following question: is it possible to identify orthographic norms by observing contemporary language use? In his discussion of post-classical Greek as a standard language, Evans concluded that "we should be building our understanding of an emerging standard language in non-literary papyri from this internal evidence much more than from the practices of classical literature". ${ }^{8}$ Whereas external orthographic norms can be found in modern dictionaries, grammars and editions of classical literature, contemporary parallels, such as the patterns of language use in documentary and literary papyri, inscriptions, and in Byzantine grammatical treatises, lexicographical works and literary manuscripts, are less accessible and they are not always considered to provide useful evidence for Greek orthographic norms. It is true that professional scribes often tried to follow conservative norms, but they also introduced various types of innovations. ${ }^{9}$ Changes in the choice of lexemes and syntactic constructions that depend on chronological and geographical diversification are found in the formulation of frequently used fixed phrases and they can be spread through scribal practices. ${ }^{10}$ In this article, I will show that similar context-dependent changes could also have played a role in orthographic variation.

\footnotetext{
${ }^{7}$ Siebenborn 1976, 91-92.

${ }^{8}$ Evans 2010, 205.

${ }^{9}$ See Leiwo 2003.

${ }^{10}$ See Vierros 2012 and Stolk 2015.
} 


\section{Corpus of documentary papyri}

The corpus for this study consists of more than 50.000 published documentary papyri in the Papyrological Navigator (www.papyri.info) dated between the third century BCE and the seventh century CE. This corpus is searchable, but the presentation of the search results could easily obscure internal orthographic patterns. Most importantly, search results do not only include the real attestations as preserved on the papyrus, but also forms found in filled abbreviations, supplements in lacunae, regularizations and other editorial comments provided in the apparatus. This means that the actual attestations become mixed with editorial judgements. Results would have to be checked manually in order to separate modern additions from the ancient writing. A new database, Trismegistos Words (www.trismegistos.org/words), has recently been developed by Alek Keersmaekers and Mark Depauw. In this database one can search for all attestations of a single lexeme and limit the search results by various criteria, such as only attestations outside abbreviations and lacunae, in order to separate real attestations from editorial supplements. ${ }^{11}$

All selected examples of variation are concerned with the variation between the graphemes $<_{1}>$ and $<_{\varepsilon l}>$. The merger of the phonemes /ei/ and /i:/ was completed in the spoken language by the mid third century BCE according to Mayser and Schmoll. ${ }^{12}$ Variation between these graphemes encountered in documents dated after the mid third century BCE should therefore be understood as spelling variation rather than reflecting different pronunciations. The choice between the spelling of $\langle 1\rangle$ and $\langle\varepsilon 1\rangle$ formed also an important

\footnotetext{
${ }^{11}$ For this article, I used the TM Words database as well as manual searches through the search results of both alternative spellings in the $P N$. Frequencies of attestations are based on the texts present in $T M$ in November 2018 (based on a scrape from $P N$ in 2016) and in the $P N$ in May 2018.

${ }^{12}$ Mayser and Schmoll 1970, 60. Teodorsson 1977, 214 dates this merger before 250 BCE in the position before consonants. Examples before vowels only start to appear around 250 BCE.
} 
part of the study of orthography by the ancient grammarians, which will allow me to compare the statements by grammarians with the actual usage of the selected lexemes in the papyri. ${ }^{13}$

Almost 30.000 editorial regularizations of spelling variation between $<_{l}>$ and $<_{\varepsilon l}>$ are collected in Trismegistos Text Irregularities (www.trismegistos.org/textirregularities). This database collects editorial regularizations of orthography and morphology from all digitalized papyrus editions. ${ }^{14}$ The choice between external and internal evidence to determine the orthographic standards in post-classical Greek can sometimes lead to conflicting results in editorial practices. ${ }^{15}$ For the current article, I searched for (i) cases in which the spelling found on a papyrus is in fact more frequently attested than the spelling of the regularization; (ii) lexemes which are regularized by editors in both directions, i.e. $<1>$ into $<\varepsilon l>$ and vice versa, and (iii) lexemes which are inconsistently regularized by (different) editors. ${ }^{16}$ These three criteria should identify words for which external and internal standards do not match or for which the spelling changed over time.

I will present five lexemes used in different contexts for which we could consider a (temporary) change in orthographic norms. Section 4 discusses a possible orthographic change in Roman dating formulae, section 5 concerns a lexeme also used in more private contexts and section 6 discusses the spelling of several derived nouns in $-(\varepsilon)$ lov.

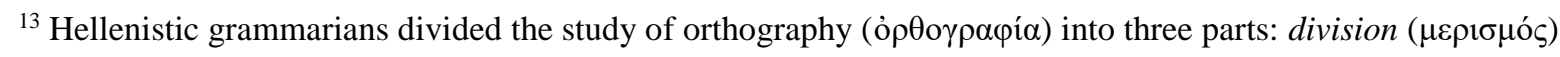

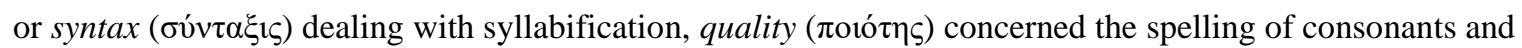

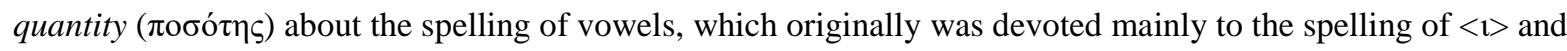
$<\varepsilon 1>$, see Siebenborn 1976, 37-41.

${ }^{14}$ See Depauw and Stolk 2015.

${ }^{15}$ See Stolk 2018.

${ }^{16}$ See also examples in Stolk 2018.
} 


\section{4. $\tau \rho(\varepsilon) \iota \sigma \kappa \alpha \iota \delta \varepsilon ์ \kappa \alpha \tau \sigma$, 'thirteenth'}

Between classical and post-classical Greek, the ordinal numbers $13^{\text {th }}$ to $19^{\text {th }}$ lost their double

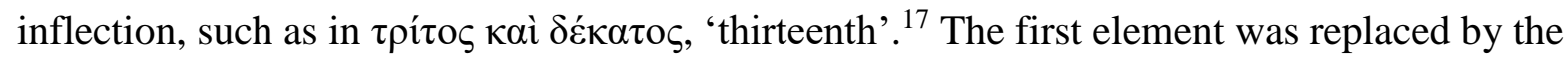
respective cardinal number, e.g. $\tau \rho \varepsilon \tilde{c} \varsigma$, 'three', used indeclinably. Historically, two spellings are attested for the indeclinable form of the Greek cardinal number 'three': with $\langle\varepsilon$ c $>$ deriving from the PIE nominative form *treies $>\tau \rho \varepsilon i \bar{c}$ and with $\left\langle 1>\right.$ from the accusative $*$ trins $>\tau \rho \tilde{i} \varsigma .{ }^{18}$ The newly formed ordinal number is attested in both variant spellings in the papyri:

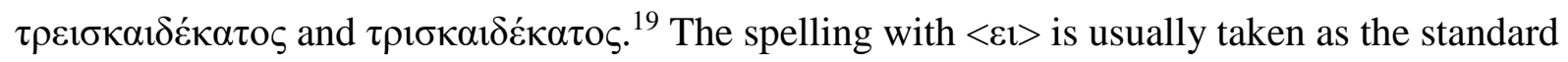
spelling in Attic-Ionic and post-classical Greek. ${ }^{20}$ The spelling with $<1>$, however, according to LSJ “occurs mostly later" and Gignac noted it in his list of attested variants in Roman and

\footnotetext{
17 The only example Gignac 1981, 202 gives of the supposedly still occurring double inflection is P.Strasb. IV

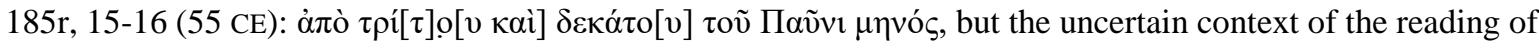
the first element makes the example highly suspicious. The editor might have considered the spelling of the $\langle 1\rangle$ instead $\langle\varepsilon \imath\rangle$ in the first element as an indication for the older form, but I will argue in the following that this is not a valid argument based on the evidence for the Roman period. Paul Heilporn has been so kind as to send me a photograph of this papyrus and confirm my suspicions. Even though there seems to be enough space for the slightly longer double inflection, the first visible letter after $\tau \rho$ corresponds better to a sigma than to an omicron

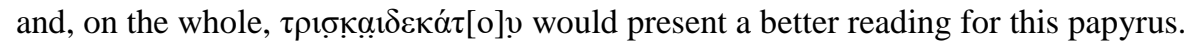

${ }^{18}$ See Beekes 2010, 1502 and Chantraine 1977, 1131. Both spellings for the cardinal number $\tau \rho(\varepsilon) 1 \sigma \kappa \alpha i \delta \varepsilon \kappa \alpha$, 'thirteen', are attested in the Iliad and Odyssey, see references in Montanari 2015, 2140. The cardinal number is replaced by the form $\delta \varepsilon \kappa \alpha \tau \rho \varepsilon i \tilde{~}$ in post-classical Greek, see Gignac 1981, 195-186, which is also attested in both spellings in papyri.

${ }^{19}$ The same spelling variation is also found for the cardinal number $\tau \rho \varepsilon \tilde{c}$, although the spelling with $\langle\varepsilon 1\rangle$ seems still more frequently found in the digital editions (1319 texts in $P N$ ) than regularizations only (563 times in Trismegistos Text Irregularities).

${ }^{20}$ See for example the main entry in LSJ s.v. and Gignac 1981, 202.
} 
Byzantine papyri. ${ }^{21}$ Even though both spellings occur frequently, editors of papyrus documents take the spelling with $\langle\varepsilon \mathrm{l}\rangle$ as the standard form and regularize the spellings with $\langle 1\rangle$ to $\langle\varepsilon l\rangle$. Did the scribes themselves consider the spelling with $\langle\varepsilon l\rangle$ or with $\langle 1\rangle$ as the norm or does the attested variation mean that both spellings were equally acceptable at any time?

There seem to be 335 attestations of the ordinal adjective 'thirteenth' in the digital editions of published documentary papyri in the Papyrological Navigator, of which 96 read

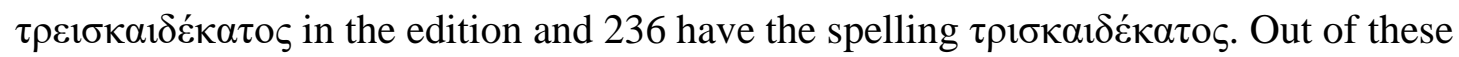
apparent 96 spellings with $\langle\varepsilon \mathrm{\varepsilon}\rangle, 37$ are in fact supplemented by the editor in a lacuna or read in an otherwise problematic context. ${ }^{22}$ The almost consistent regularization easily obscures the fact that the spelling $\tau \rho ı \sigma \kappa \alpha \iota \varepsilon ́ \kappa \alpha \tau o \varsigma$ is found in 218 papyri in a certain context, while $\tau \rho \varepsilon ı \sigma \kappa \alpha \iota \delta \varepsilon ́ \kappa \alpha \tau о \varsigma$ features only in 59 certain examples. The preference for the spelling with $<1>$ becomes even more clear when we look at the chronological distribution of the attestations in documents before and after the start of Roman rule in Egypt.

During the Ptolemaic period in Egypt, the cardinal number is always spelled as

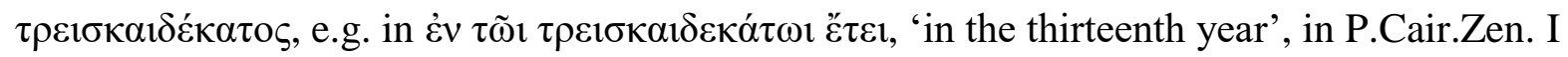

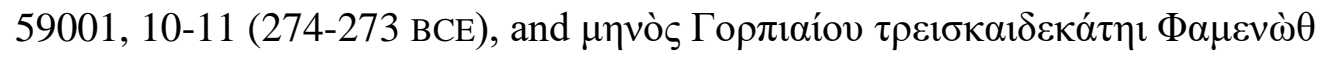

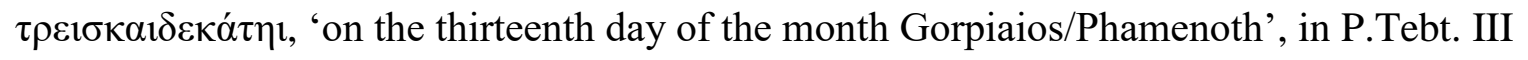

\footnotetext{
${ }^{21}$ Gignac 1981, 202.

${ }^{22}$ The same phenomenon can be observed in the modern editions of the grammarians. Erbse prints in his edition

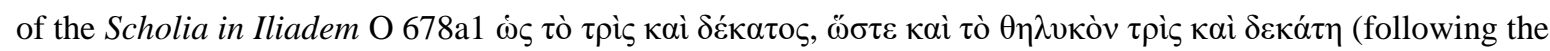
spelling of the manuscript), while Lentz (GG III.II 97, 12-13) takes over the spelling with <ع> from Lehr's

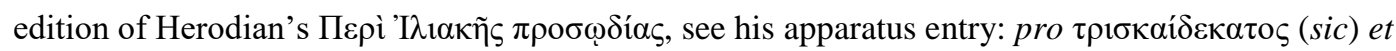

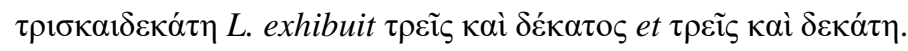




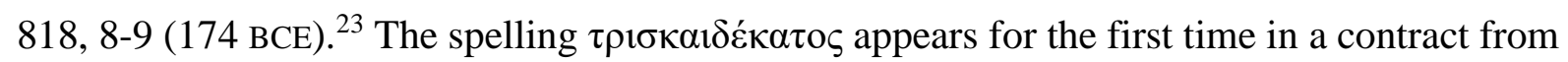
Alexandria in a dating formula referring to the thirteenth year of the emperor Augustus: $\tilde{\varepsilon} \omega \varsigma$

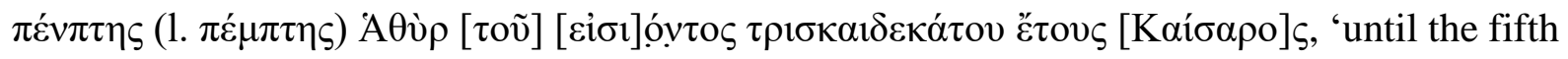
of (the month) Hathur of the coming thirteenth year of Caesar' (BGU IV 1143, 11-13; 19-18 BCE, see $B L$ XI 25). ${ }^{24}$ The spelling with $\langle 1>$ continues in Roman dating formulae for the

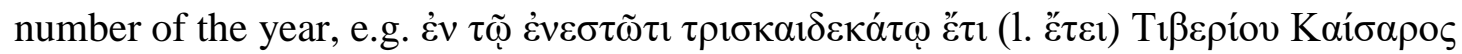
$\Sigma \varepsilon \beta \alpha \sigma \tau$ ov in P.Mich. V 337, 13-14 (26 CE, see BL XII 122), as well as for the day of the

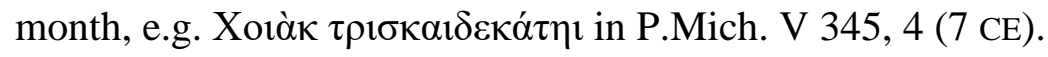

During the first three centuries of the Roman period, we find a total of 122 attestations of the spelling with $\langle 1\rangle$ and only six certain attestations of the spelling with $\langle\varepsilon 1\rangle$ in four different texts. ${ }^{25}$ I would argue that it is more sensible to assume that there were four scribes who produced six examples of a spelling which was unconventional at the time rather than maintaining that more than a hundred other scribes did. For instance in P.Mich. V 354, 29-30 (52 CE), the spelling of $\tau \rho \varepsilon 1 \sigma \kappa \alpha 1 \delta \varepsilon \kappa \alpha ́ \tau o v$ is found in combination with numerous other non-

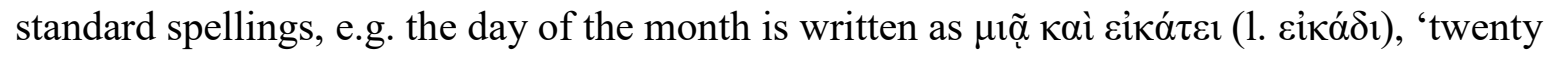
first' (1. 32). Confusion between the variant spellings of the element 'three' in different formations could explain these few exceptions to the rule. The spelling with $\langle 1\rangle$ thus seems to

\footnotetext{
${ }^{23}$ The readings of all attestations cited in this article are based on the digital editions in the Papyrological Navigator $(P N)$, but have been checked in the printed editions, on a photograph of the papyrus (if available) and for any corrections collected the Berichtigungsliste der Griechischen Papyrusurkunden aus Ägypten (BL). Translations are added by the author, but may be based on the translation of the edition if available.

${ }^{24}$ The spelling variant $\delta \varepsilon \kappa \alpha \tau \rho \tilde{\iota} \varsigma$ also appears for the first time in documents during the first century CE, but the variants $\delta \varepsilon \kappa \alpha \tau \rho \varepsilon \tilde{\varsigma} \zeta$ and $\delta \varepsilon \kappa \alpha \tau \rho \tilde{\iota} \varsigma$ still seem to have been attested in more or less equal quantities during the Roman period (each attested in 21 papyri during the first three centuries CE).

${ }^{25}$ P.Mich. V 354, 29-30 (Tebtynis, 52), PSI 10 1134, 8 and 17 (Tebtynis, 91), P.Hamb. I 71, 14 (Philadelpheia,

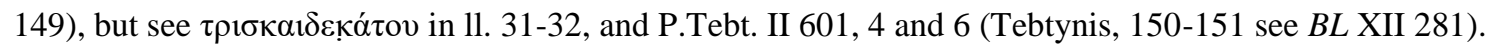


have become the standard spelling of this lexeme from the beginning of Roman imperial rule in the Eastern Mediterranean. ${ }^{26}$

The use of the spelling $\langle 1\rangle$ during the Roman period could have been aided by analogy to

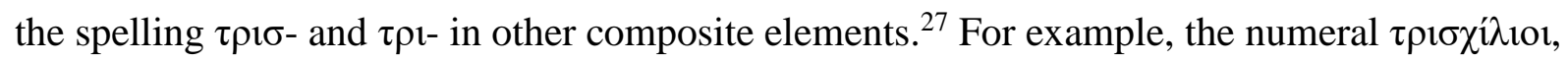
'three thousand', has always had a normative spelling with $\langle 1\rangle$, because it derives from the

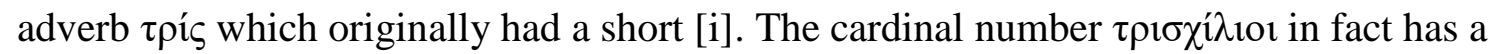
similar distribution of spelling variation to $\tau \rho \iota \sigma \kappa \alpha \iota \delta \varepsilon ́ \kappa \alpha \tau o \varsigma$ in papyrus documents from the Roman period (I-III CE), with 114 attestations of the spelling with $<1>$ and the spelling with $<\varepsilon \mathrm{l}>$ occurring in only three texts. These parallel frequencies of occurrence give us a good reason to consider the spelling $\tau \rho ı-$ in $\tau \rho \iota \sigma \kappa \alpha \iota \delta \varepsilon ́ \kappa \alpha \tau o \varsigma$ just as conventional as the spelling of $\tau \rho ı \sigma-$ in $\tau \rho ı \sigma \chi i \lambda ı เ$ in papyri from the Roman period, albeit with different etymological origins.

\footnotetext{
${ }^{26}$ A search for both forms in inscriptions collected by the Packard Humanities Institute at https://inscriptions.packhum.org/ (accessed November 2018) suggests that this orthographic norm was also found outside of Egypt. If the spellings of the recorded inscriptions in PHI can be trusted, they largely confirm this pattern with only attestations of the spelling $\langle\varepsilon \mathrm{l}\rangle$ ( 7 times) in the period BCE changing to 10 attestations of $<1>$ and only 2 with $\langle\varepsilon 1>$ in the period CE in inscriptions from Asia Minor and the Near East. A similar pattern can be found in inscriptions from mainland Greece and the Aegean islands. The spelling $\langle\varepsilon l\rangle$ (16 times) is more frequently attested than the spelling $\langle 1\rangle$ (3 times) in inscriptions from the Aegean Islands during the III-II BCE. In inscriptions from mainland Greece, we only find the spelling with $<_{1}>$ from the first century CE onwards, but both spellings are attested in different periods before that. Better digital resources for inscriptions would allow us to study these types of orthographic variation at a larger scale.

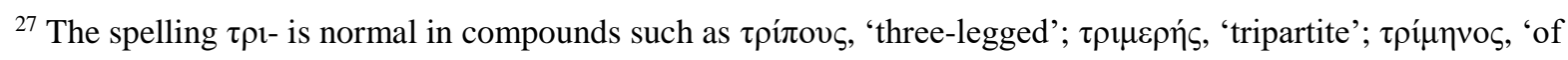

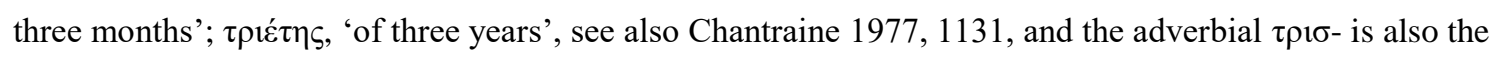

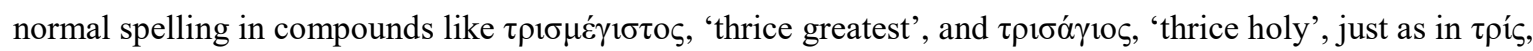
'three times'.
} 
From the fourth century onwards papyrus documents are dated by their indiction year. Initially, this new dating formula does not change the spelling of the number: during the fourth century there are 21 attestations of the spelling with $\langle 1\rangle$ and only 1 of the spelling $\langle\varepsilon 1\rangle$ (SB XVIII 13252, 3 and 13; 369-370). During the fifth century things start to change. The common spelling with $\langle 1\rangle$ is continued in the majority of the documents from Oxyrhynchos during the fifth (9 with $\langle 1\rangle$ and 1 with $\langle\varepsilon l>)$ and sixth centuries ( 16 with $\langle 1\rangle$ and 3 with $\langle\varepsilon l>$ ). In the Hermopolite nome, however, the spelling with $\langle\varepsilon \mathfrak{}\rangle$ is found again in a letter from the council of Hermopolis from the end of the fourth century (P. Select 10, 11;399-400, see $B L$ VIII 200) and a tax receipt (SB XXII 15314, 3; 444-445) and lease contract (BGU XII $2160,10 ; 488)$ from the fifth century and continues to be more frequent during the sixth century ( 8 documents with $\left\langle\varepsilon 1>\right.$ against 4 with $\left\langle 1>\right.$ ). ${ }^{28}$

The change from the Hellenistic kingdoms to the Roman Empire seems to mark the change from the spelling $\tau \rho \varepsilon เ \sigma \kappa \alpha \iota \delta \varepsilon ́ \kappa \alpha \tau o \varsigma$ to a predominant spelling of $\tau \rho \iota \sigma \kappa \alpha \iota \delta \varepsilon ́ \kappa \alpha \tau o \varsigma$ in documentary papyri. Which aspect of the linguistic interaction between Greeks and Romans may have triggered this change — and possibly other changes — is a question that needs to be studied in its own right. While Roman imperial rule assisted in the spread of Greek orthographic norms across the Eastern Mediterranean, from the fifth century onwards regional scribal practices prevail and the orthographic norms seem to have changed again accordingly.

\footnotetext{
${ }^{28}$ The spelling with $\langle 1>$ is only found in two documents from the Hermopolite possibly dating to the fifth century, namely in BGU XII 2144, 3 and PSI I 66, 24 (see BL VIII 392). Variation is also found in other regions, but there is not enough material to determine the most frequent pattern in other regions during the fifth century CE.
} 


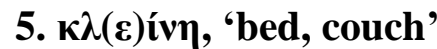

Full dating formulae are mostly found in documents produced in professional contexts.

Changes in norms and conventions can spread relatively easily through scribal training and shared practices. Even though we are less likely to encounter widespread changes from one spelling to another in private contexts, there are some lexemes for which one could argue for a change in spelling practices.

The noun $\kappa \lambda i v \eta$, 'that on which one lies' (LSJ s.v.), derives from the present form of the

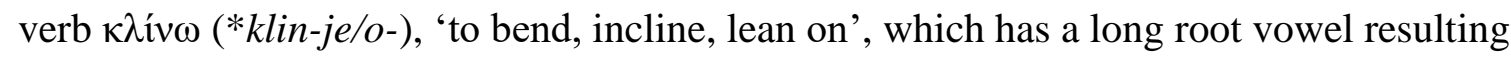
from compensatory lengthening after merger of the nasal with the yod of the present suffix. ${ }^{29}$ Root vowels $\langle l\rangle$ and $\langle\varepsilon l\rangle$ are found for the derivatives without a nasal, but the (long) root vowel $\left\langle 1>\right.$ is represented in most derivatives with the nasal, such as the noun $\kappa \lambda i$ iv ${ }^{30}$ In the papyri, both the present verb as well as the derived noun and adjectives are attested multiple times with both spellings $<_{1}>$ and $<\varepsilon 1>$ in the root, compare, for example, the variant spellings

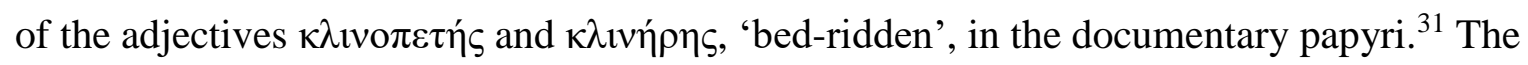
noun $\kappa \lambda i v \eta$ occurs most frequently of all, especially in papyri dated between the third century BCE and the third century CE, and mostly in private letters and lists of items.

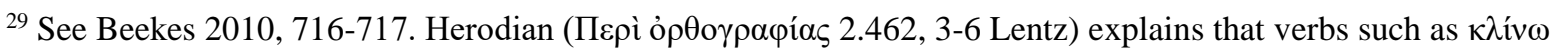

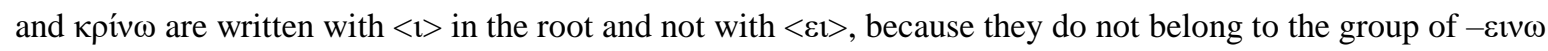
verbs which have a future form with $\langle\varepsilon\rangle$ in the stem (cf. pres. $\kappa \tau \varepsilon$ ív $\omega$, fut. $\kappa \tau \varepsilon v \tilde{\omega})$.

${ }^{30}$ See Chantraine 1970, 544.

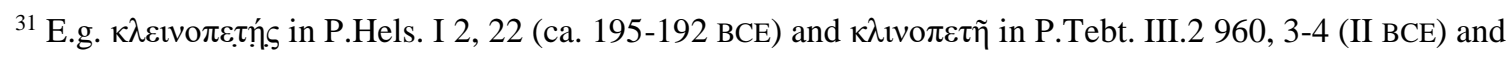

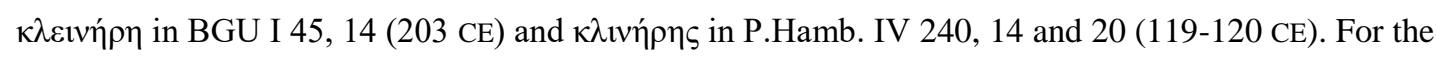
distribution of these different lexemes with a similar meaning in literary and documentary sources from the Ptolemaic and Roman periods see Maravela 2018, 22-24.
} 
The literary papyri found in Herculaneum, dated to the first century BCE, show the classical spelling $\kappa \lambda i ́ v \eta$, see e.g. P.Herc. 182,807 and $1050 .{ }^{32}$ In the documentary papyri, both spellings are found during the Ptolemaic period (10 times $\langle\varepsilon l\rangle$ and 11 times $\langle 1\rangle)$. The spelling with $<_{1}>$ is attested, for example, in the lists of items in P.Cair.Zen. IV 59692, 13

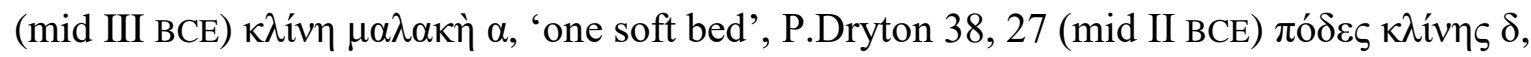

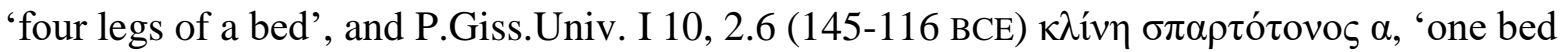
slung on ropes'. The spelling with $\langle\varepsilon l>$ is found, for example, in the letters P.Cair.Zen. III

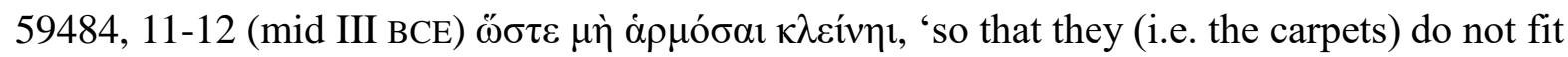

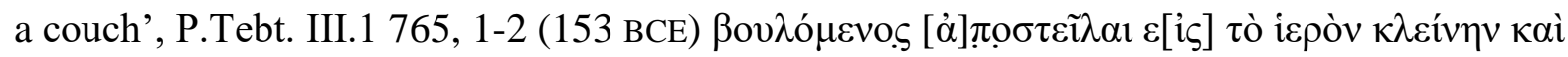
$\tau v ́ \lambda \eta v$, 'intending to send a bed and a cushion to the temple', and SB XVIII 13168, 5 (123

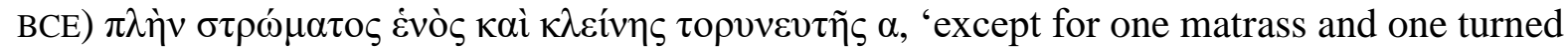
bed'.

During the Roman period, the spelling with $\langle\varepsilon l\rangle$ becomes much more frequent with 30 attestations against 5 with $<_{1}>$. The spelling with $<_{\mathfrak{l}}>$ is still used to refer to a concrete object,

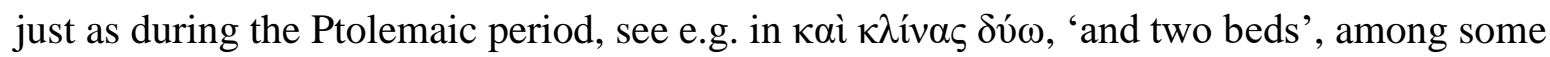

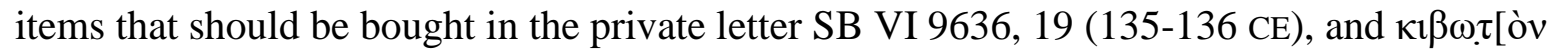

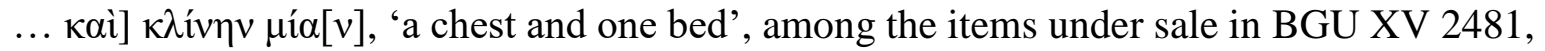
10-11 (138-161 CE). The spelling $\langle\varepsilon \mathrm{c}>$ is found in similar contexts, such as in inventory lists

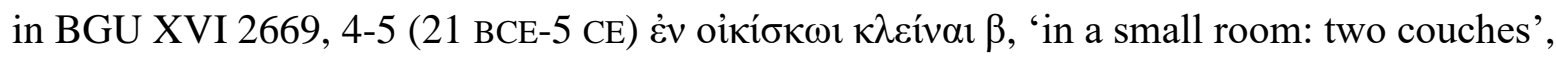

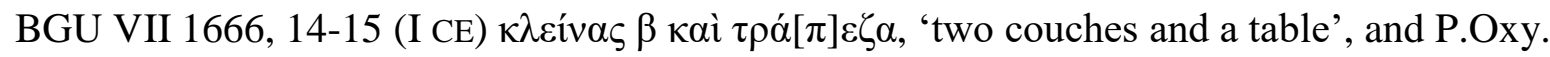

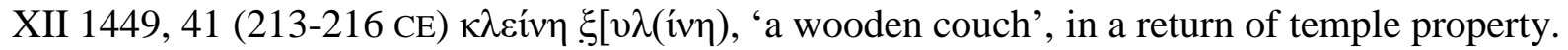

The large number of attestations with the spelling $\langle\varepsilon l\rangle$, however, is caused by a different sense of the word. The lexeme $\kappa \lambda i$ iv $\eta$ can also be used for the dining couches at a theoxenion,

\footnotetext{
${ }^{32}$ The attestations for literary papyri are based on the results in the $D C L P$ at www.litpap.info, accessed November 2018.
} 
a banquet or sacred meal held in a temple or sanctuary. ${ }^{33}$ By metonymic extension, these couches become to refer to the event itself (previously called $\pi \varepsilon \rho i ́ \delta \varepsilon ı \pi v o v)$. The spelling $\kappa \lambda$ cívๆ is found referring to such an event in 18 dinner invitations from Oxyrhynchos, e.g.

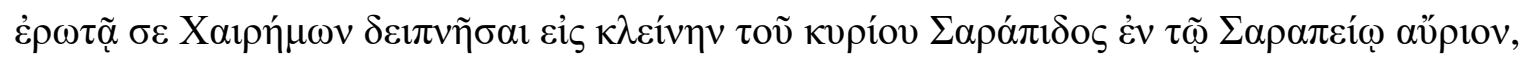
'Chairemon invites you to have dinner at a banquet of the lord Sarapis in the Sarapeion tomorrow', in P.Oxy. I 110, 1-3 (II CE). A reference to the meaning 'banquet' is also found in a letter from the Arsinoite nome in which Ptolemaios informs his father about a banquet in the

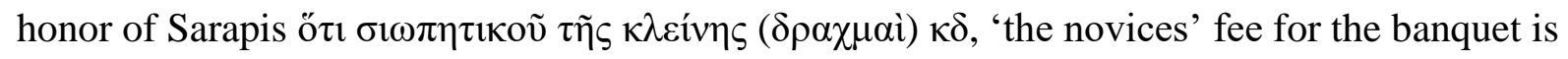

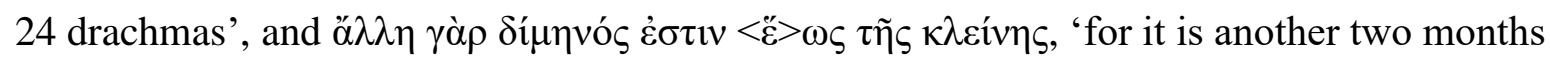
until the banquet' in P.Mich. VIII 511, 16-18 and 3-4 (first half III CE).

Although both spellings of $\kappa \lambda(\varepsilon)$ ív 'bed, couch' are used during the Ptolemaic and Roman periods, the variation between $\langle\imath\rangle$ and $\langle\varepsilon l\rangle$ does not seem to be entirely accidental. For the new more abstract meaning of 'banquet', the spelling with $<\varepsilon l>$ is preferred without exception. In this case, the new meaning of the lexeme seems to have aided the spread of a new standard spelling.

\section{Derived nouns in $-(\varepsilon)$ เov}

Even though almost every lexeme containing the phoneme /i/ can be spelled in various ways in documentary papyri, some elements seem more vulnerable to itacism than others. Variation is especially common with derived nouns in $-(\varepsilon) 1 \alpha$ and $-(\varepsilon) 10 v$, as already observed by Palmer, because variant spellings may have been present in the Greek language for some time.$^{34}$ He suggests some general principles to decide about the orthography of nouns in $(\varepsilon) 1 \alpha$, but fails to find a consistent solution for the nouns in $-(\varepsilon) 10 v$ :

\footnotetext{
${ }^{33}$ See Montserrat 1992.

${ }^{34}$ Palmer 1945, 52-58; 70-77.
} 
No satisfactory solution is possible in the choice between $-10 \mathrm{v}$ and -ecov, the suffixes which characterize inter alia names of establishments, workshops, \&c., since Attic, too, possessed both suffixes (see p. 56). It is true that the two forms are often distinguished by the position of the accent; but here, too, analogical displacement has blurred the original distinctions.... If we have no indication of the position of the accent, the problem is insoluble, and only an arbitrary decision is possible: in MGr. -

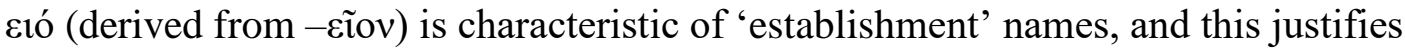
us, perhaps, in interpreting such nouns in $-10 \mathrm{v}$, clov, \&c., in our texts as -عĩov. ${ }^{35}$

The suffix $-10 v$ with accent on the antepenultimate is used for denominative nouns in a wide variety of meanings, such as the place connected to a person or nomen agentis, instrument, means, household objects, materials, affiliation by category or similarity, and to form

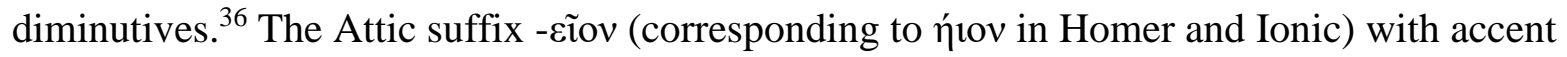
on the penultimate is similar in form and meaning and seems to alternate with - $10 \mathrm{v}$ in postclassical Greek. ${ }^{37}$ The suffix - - ĩov may be particularly productive in papyri to form a noun denoting a certain place of action, such as a workshop, as also referred to by Palmer (see above). ${ }^{38}$

The two suffixes can be very difficult to keep apart, especially in rare words or new formations. Palmer's conclusion that "only an arbitrary decision is possible" in some of these cases may be true when a modern scholar intends to choose a single orthographic form for the lemma of a lexeme with attestations spanning more than two thousand years. Synchronically,

\footnotetext{
${ }^{35}$ See Palmer 1945, 4-5.

${ }^{36}$ See Chantraine 1933, 54-68 and Moulton 1929, 341-344.

${ }^{37}$ See Chantraine 1933, 60-61

${ }^{38}$ See also Moulton 1929, 344.
} 
however, it might be possible to identify some of the orthographic conventions for individual lexemes that are followed by scribes and scholars at various moments in time. ${ }^{39}$

\section{$6.1 \gamma \lambda \omega \sigma \sigma 0 \kappa \mu(\varepsilon) \imath v v$, 'casket'}

The difficulty to separate the two suffixes $-10 \mathrm{v}$ and -Eĩov can be illustrated by derivations from the noun $\gamma \lambda \omega \sigma \sigma o ́ \kappa o \mu o v$. The lexeme $\gamma \lambda \omega \sigma \sigma o ́ \kappa o \mu o v$ is regularly found in papyri, already from the third BCE (e.g. $\gamma \lambda \omega \sigma \sigma o ́ \kappa о \mu \alpha \gamma$ ' 3 chests' in a list of pledged items in P.Worp 13, 44) until the sixth century CE (e.g. $\gamma \lambda \omega \sigma o ́ \kappa o \mu o v ~ \chi \alpha ́ \rho \tau(\omega v)$ 'box for documents' in a description of the props used on stage in SB XXVI 16648, 17, cf. Perrone 2011, 142 n. 51). ${ }^{40}$ The derived noun $\gamma \lambda \omega \sigma \sigma о \kappa о \mu(\varepsilon)$ lov is only found in documentary papyri, the medical works by Galen and accounts of its spelling and meaning by lexicographers and grammarians. In Pollux' Onomasticon (10.153-154 Bethe), the noun is mentioned with a reference to Lysippus' Bacchantes, where it serves as a 'case to keep the reeds or tongues of musical instruments' (see also LSJ s.v.), compare also the entry in Phrynichus:

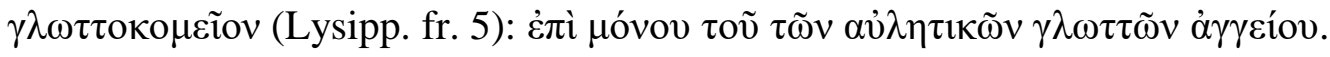

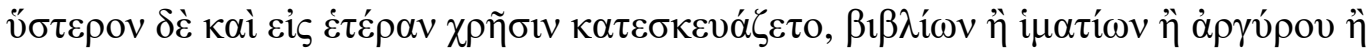

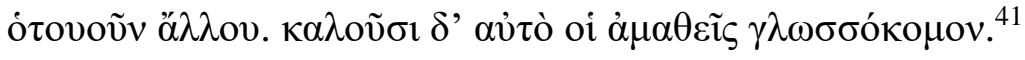

\footnotetext{
${ }^{39}$ Since accents are not visible in documentary papyri and the contemporary pronunciation can be difficult to establish with certainty, the accent is left out during the discussion of ambiguous cases in the following sections.

${ }^{40}$ On the meaning of $\gamma \lambda \omega \sigma \sigma o ́ \kappa o \mu o v$ in the papyri see also Vandorpe, P.Dryton, p. 283.

${ }^{41}$ Praep. Soph. p. 58, 8-11 Borries. Translation by author.
} 
$\gamma \lambda \omega \tau \tau$ око $\mu \varepsilon i ̃ v$ (Lysipp. fr. 5): only the box for the reeds of flutes. Later it is also applied to other usages, for books or cloths or money or whatever else. The ignorant

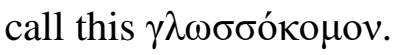

Phrynichus adds here that the word actually has a much wider use than the one in the literary

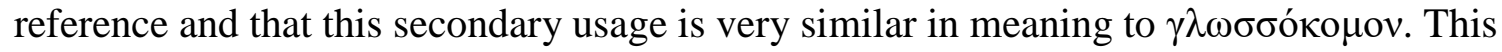
more general meaning indeed corresponds to what we find in papyri and Galen. Preisigke

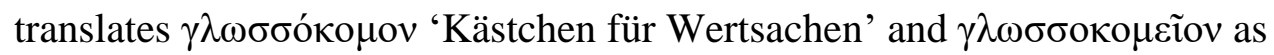
'Schmuckkästchen'. ${ }^{42}$ It is unclear whether there would be a significant difference in size or form between these two objects, but it is possible that $\gamma \lambda \omega \sigma \sigma o \kappa o ́ \mu 10 v$ was understood as a

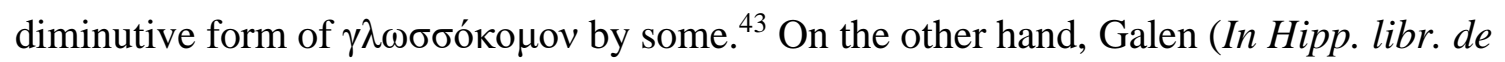
fract. comm. ii. LXIV, XVIII.2 p. 502 Kühn) uses the word $\gamma \lambda \omega \sigma \sigma o \kappa o ́ \mu o v$ for a type of wooden box fixed around the leg to heal fractures and adds that it makes no difference whether it is called $\gamma \lambda \omega \sigma \sigma o ́ \kappa о \mu о v$ or $\gamma \lambda \omega \sigma \sigma o \kappa o ́ \mu 10 v$.

Even though both words are attested several times in documentary papyri, strikingly, the

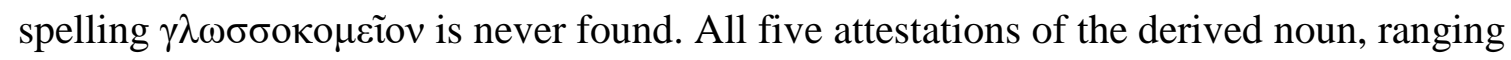
from the second century BCE until the sixth century CE, consistently spell $\gamma \lambda \omega \sigma \sigma o \kappa o ́ \mu 10 v .{ }^{44}$

\footnotetext{
${ }^{42}$ Preisigke 1925, 299.

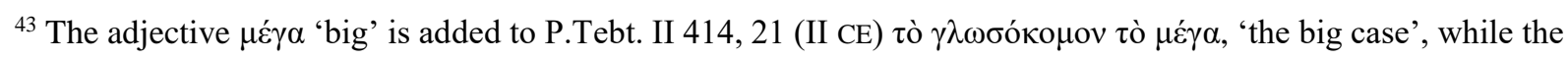
adjective $\mu 1 \kappa \rho o ́ \varsigma$, 'small', is added to derived noun $\gamma \lambda \omega \sigma \sigma o \kappa o ́ \mu 1 o v$ in P.Oxy. LIX 4005, 6 (VI) $\mu 1 \kappa \rho o ̀ v ~ \delta \dot{~}$

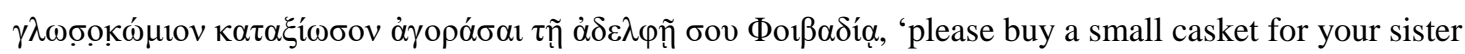
Phoebadia'. The abbreviation $\gamma \lambda \omega \sigma \sigma o ́ \kappa o(\mu o v) \mu t(\kappa \rho o ̀ v) ~ \varepsilon ̇ v ~ \tilde{\omega} \beta \beta(\beta \lambda i ́ \alpha)$, 'a small casket containing sheets of papyrus', which was kept inside a larger box in P.Dryton 42, 12 (134 BCE), may have referred to either one of the nouns. Most references do not give an accurate account of the relative size of the two objects.

${ }^{44}$ See BGU VI 1300, 9 (210 or 193 BCE), BGU III 824, 9-10 (97-98 CE; BL VIII, 34-35), P.Lond. II 191 (p. 264), 14 (103-117 CE), P.Cair.Masp. I 67006 V 64 and 89 (ca. 567 CE) and P.Oxy. LIX 4005, 6 (VI CE).
} 


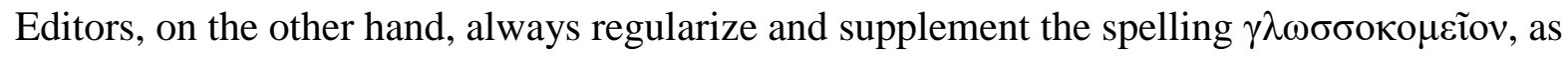
in the Lysippus fragment, probably following dictionaries and/or Palmer. ${ }^{45}$ Photius, summarizing an earlier work of the grammarian Helladius, also rejects the variant spelling (and pronunciation) of the -lov suffix with antepenultimate accentuation:

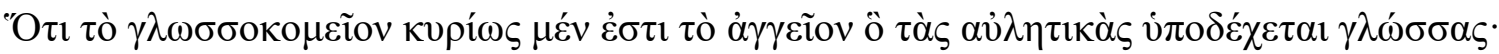

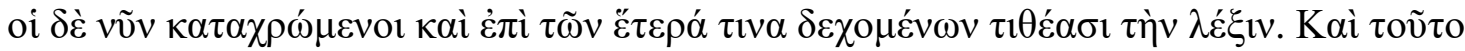

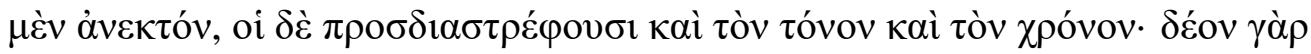

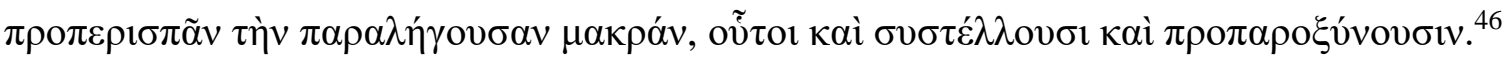

the $\gamma \lambda \omega \sigma \sigma о к о \mu \varepsilon i ̃ v$ in the proper sense is a box in which the reeds of flutes are collected, but now users making excessive use of it also apply the word to containers of other items. And this is acceptable, but they also pervert the accent and vowel length. For it should have a circumflex accent on the long penultimate, some also shorten it and give it an acute accent on the antepenultimate.

The use of the lexeme for containers of various items seems to have coincided with the pronunciation of an acute accent on the antepenultimate syllable and shortening of the

\footnotetext{
${ }^{45}$ Palmer 1945, 56. The spelling with $\langle\varepsilon 1>$ is found in LSJ, Sophocles 1914, Preisigke 1925, and the most recent $D G E$. Only in $D G E$, two examples (in an inscription and on a papyrus) are given of the orthographical variant with $\langle 1>$ amongst other (more extreme) examples of attested variant spellings. The spelling with $\langle\varepsilon l>$ seems also

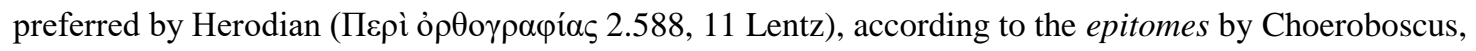

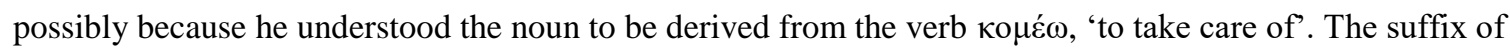

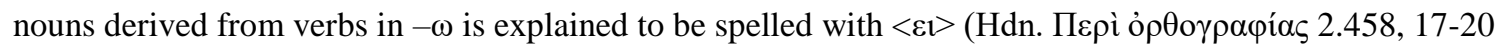
Lentz).

${ }^{46}$ Bibl. 279, 532a, 6-12 Henry. Translation by author.
} 
penultimate syllable, as expected for derived nouns with the suffix $-10 \mathrm{v}$. The shortening of the vowel of the penultimate would also be consistent with the spelling $\langle 1\rangle$ in the papyri. Thus it

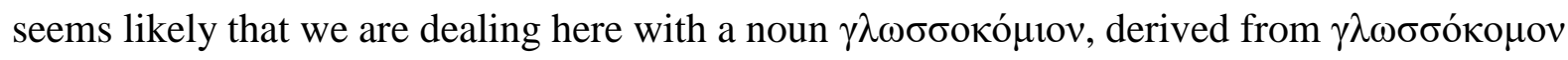
with the suffix $-10 \mathrm{v}$. This noun $\gamma \lambda \omega \sigma \sigma o \kappa o ́ \mu 10 v$ may have been similar in form and meaning to another derived noun $\gamma \lambda \omega \sigma \sigma o \kappa o \mu \varepsilon i ̃ o v$, which we only know from the literary reference discussed by grammarians. This other noun seems to have been formed with the suffix $-\varepsilon i ̃ o v$, perhaps with a more elevated meaning. For all we know, the usage of this other noun seems to have been much more limited than the post-classical Greek form that is found in documentary papyri and Galen. There may be no need to identify these attestations of the word in common usage with the single literary occurrence in Attic comedy, as grammarians have led us to believe.

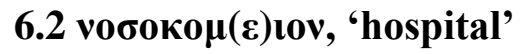

A similar formation of the verb ко $\mu \varepsilon \dot{\varepsilon} \omega$ 'to take care of' and the suffix $-(\varepsilon) 10 v$ is found vобоко $\mu \varepsilon$ iov 'hospital' or 'place for taking care of the sick'. According to the orthographic principles by Herodian, the suffix of nouns derived from verbs in $-\omega$ is spelled with $\langle\varepsilon \imath\rangle$

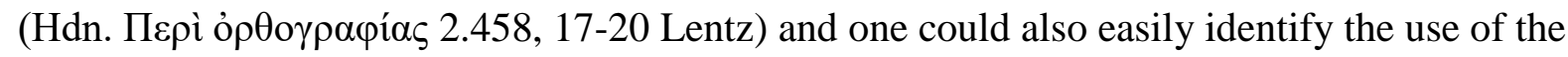

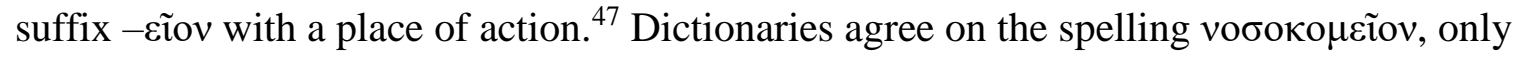
Preisigke mentions an alternative spelling in his supplement. ${ }^{48}$

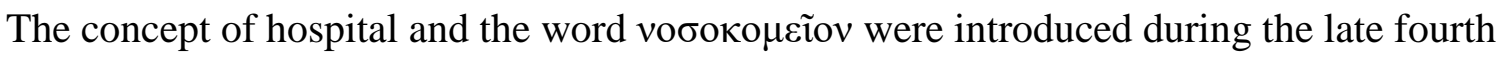
century CE, but it seems to have taken until the sixth century until an institution with this name was put into practice at a larger scale. ${ }^{49}$ The lexeme appears 50 times in papyri dated to

\footnotetext{
${ }^{47}$ See Palmer 1945, 57.

${ }^{48}$ Cf. LSJ s.v., Lampe 1961, 922, and Sophocles 1914, 786; Preisigke 1931, 262.

${ }^{49}$ See Miller 1985, 25; van Minnen 1995.
} 
the sixth and seventh centuries. ${ }^{50}$ Only once, we have a doubtful occurrence of the spelling

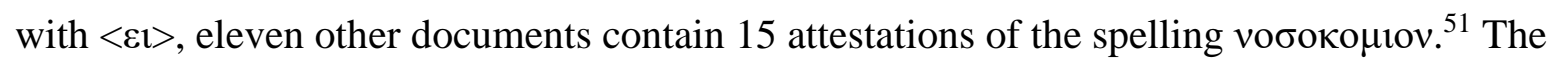
remaining attestations concern an abbreviated or incompletely preserved form of the word, invariably supplemented as vобоко $\mu \varepsilon \tilde{o v}$ by the editors.

Since the attestations of vобокоцюv clearly outnumber any evidence for the use of vобоко $\mu \varepsilon i ̃ o v$ and they are found in various places in Egypt (Arsinoite, Hermopolite and Oxyrhynchite), it seems that vобоконюv should be understood as the standard spelling in the sixth and seventh century papyri based on documentary evidence. Just as for the derived noun

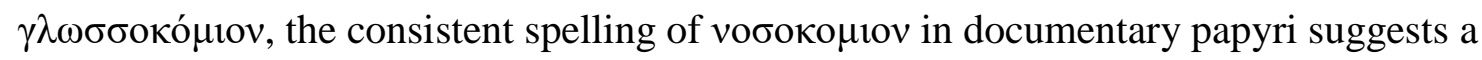
derivation with the suffix - iov. Whether the word was also pronounced with an antepenultimate accent at the time is more difficult to establish with certainty. ${ }^{52}$

\footnotetext{
${ }^{50}$ Considering this rather strict chronological distribution of the attestations of the lexeme, a date to the sixth or seventh century should be reconsidered for the few examples with (uncertain) paleographical dates to earlier periods. The handwriting of PSI I 84 seems to fit a date to the sixth-seventh century better than the fourth-fifth,
} cf. also its parallel P.Oxy. XVI 2055, dated to the sixth century. The dating of SB I 4869 (IV-VII), SB I 4903 (IV-VII) and SB I 4904 (IV-VII) could be narrowed down to the sixth-seventh century.

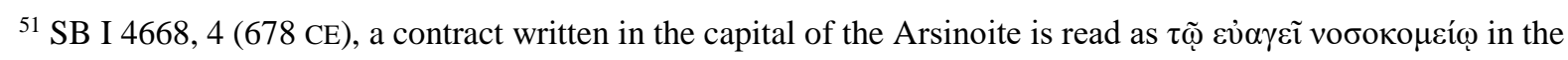
edition. This spelling, however, was not present in the editio princeps by Wessely in 1888 (Revue égyptologique 5, p. 139, no. 33), but it only appeared in a re-edition published by the same editor in 1889 (Pariser Papyri, p. 125, no. 33) and is taken over in SB I. Unfortunately, no photograph is available of this text to check the suspicion that this sudden change in spelling from one edition to the other may have been accidental.

${ }^{52}$ Due to the lack of evidence for accentuation, it is difficult to be sure about the position of the accent. At first, one would be inclined to assume an antepenultimate accentuation for nouns with the suffix -1ov, as also assumed for $\gamma \lambda \omega \sigma \sigma o \kappa o ́ \mu 10 v$ (see 6.1). The Modern Greek vобоко $\mu \varepsilon$ ío has a penultimate accentuation in accordance with the spelling with $\langle\varepsilon \imath>$, but this does not exclude the possibility of an antepenultimate accentuation (voбoкó $\mu 10 v$ ) in earlier periods. On the other hand, the difference between post-classical and Modern Greek may only have

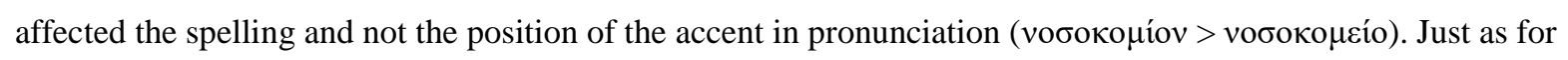




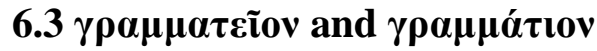

The variation between the $\gamma \rho \alpha \mu \mu \alpha \tau \varepsilon i ̃ o v$ and $\gamma \rho \alpha \mu \mu \alpha ́ \tau$ เov poses a more complex case of the spelling of the suffix. Since the works of Herodian and Pollux, grammarians and lexicographers have provided explanations for the meaning and spelling of this lexeme. A prominent idea in these works is that there are two separately derived nouns, $\gamma \rho \alpha \mu \mu \alpha \tau \varepsilon i ̃ o v$ and $\gamma \rho \alpha \mu \mu \alpha$ ciov, of which one has a diminutive meaning and the other does not. Derivatives from nouns in $-\mu \alpha$ without a diminutive meaning are spelled with $\langle\varepsilon l\rangle$ and a penultimate accent (e.g. $\gamma \rho \alpha ́ \mu \mu \alpha / \gamma \rho \alpha \mu \mu \alpha \tau \varepsilon i ̃ o v)$, while derivatives of the same nouns with a diminutive meaning

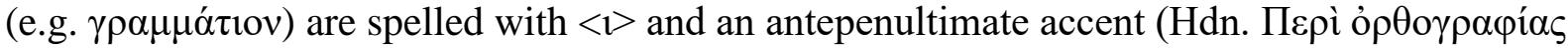
2.458, 29-33 Lentz).

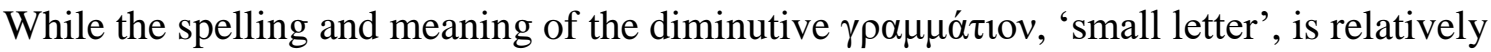
straightforward, the meaning and spelling of the non-diminutive suffix $-(\varepsilon)$ tov have been subject to variation and change in post-classical Greek. According to the dictionaries (see e.g.

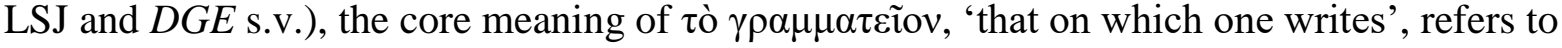
writing tablets and, more specifically, to 'written documents' of various types, such as bonds, contracts and testaments. Especially in this last meaning, the lexeme is 'frequently spelled $\gamma \rho \alpha \mu \mu \alpha ́ \tau ı v^{\prime}$ according to LSJ s.v. 2. Preisigke even has separate entries for the lexeme in both spellings with the roughly the same meaning 'Schriftstuck, Urkunde'. ${ }^{53}$ Does this mean that these were indeed two nouns derived with different suffixes in similar meanings or that there was one derived noun attested in different spellings?

$\gamma \rho \alpha \mu \mu \alpha \tau$ íov, the spelling Nocokomion is commonly found in Coptic without omission of the <o>, cf. 6.3. If this lack of evidence is to be taken as an argument, it would point towards a penultimate accentuation at the time.

${ }^{53}$ Preisigke 1925, 307-308. 


\subsubsection{A scribe's office}

The first observation that can be made is again a noticeable difference in attestations between the Ptolemaic and Roman periods. During the Ptolemaic period, the lexeme is only attested once. P.Corn. 1, 9 (257 BCE) contains an daily record of the oil for lightning provided by the finance minister Apollonios to various people and places in his service, such as the eic $\tau$ tò

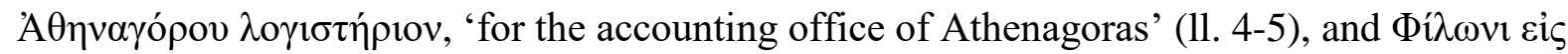

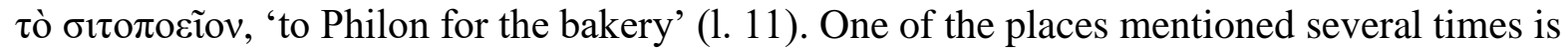

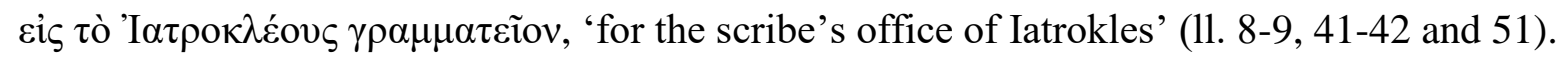
This seems to be a physical place where the scribe Iatrokles was working. The meaning of the suffix $-\varepsilon 10 v$ as 'place of action' derived from $\gamma \rho \alpha \mu \mu \alpha \tau \varepsilon u ́ \varsigma$, 'scribe', is mentioned by the grammarians since Herodian and $\gamma \rho \alpha \mu \mu \alpha \tau \varepsilon i ̃ o v$ is often used as an example to illustrate the semantics behind this type of derivation:

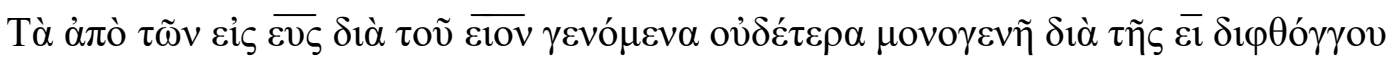

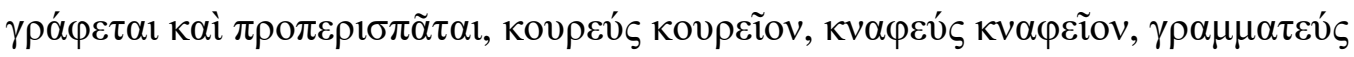
$\gamma \rho \alpha \mu \mu \alpha \tau \varepsilon \overline{o v}, \beta \alpha \lambda \alpha v \varepsilon v ́ \varsigma \beta \alpha \lambda \alpha v \varepsilon i ̃ o v, \beta \alpha \varphi \varepsilon v ́ \varsigma \beta \alpha \varphi \varepsilon i ̃ o v .{ }^{54}$

the neuter words with $-\varepsilon 10 v$ derived from words in $-\varepsilon v \varsigma$ with one gender are written with

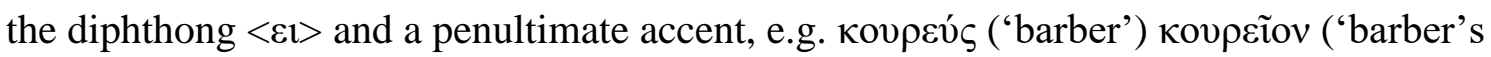

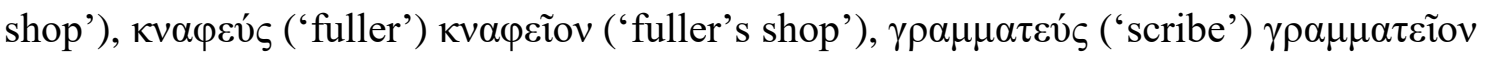
('scribe’s office’), $\beta \alpha \lambda \alpha v \varepsilon v ́ \varsigma$ ('bath-man’) $\beta \alpha \lambda \alpha v \varepsilon i ̃ o v$ ('bathing room’), $\beta \alpha \varphi \varepsilon v ́ \varsigma$ ('dyer’)

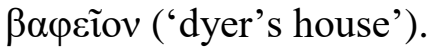

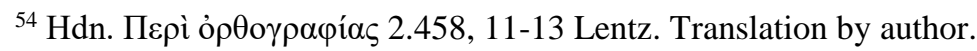


In these examples, the suffix - $-\varepsilon 10 v$ functions as a locative derivative (e.g. $\gamma \rho \alpha \mu \mu \alpha \tau \varepsilon i o v)$ of agent nouns (e.g. $\gamma \rho \alpha \mu \mu \alpha \tau \varepsilon v ́ \varsigma)$. This analogical explanation works very well for the example in the Ptolemaic papyrus (see supra), but it seems to have limited use to establish the spelling of the noun in later periods, since $\gamma \rho \alpha \mu \mu \alpha \tau \varepsilon i ̃ o v$ is not attested any more in this meaning in documentary papyri after the third century BCE. ${ }^{55}$

\subsubsection{Tablets and papyrus}

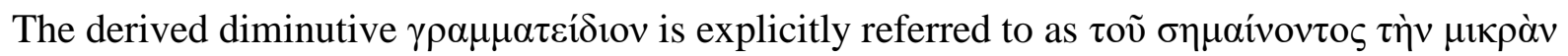

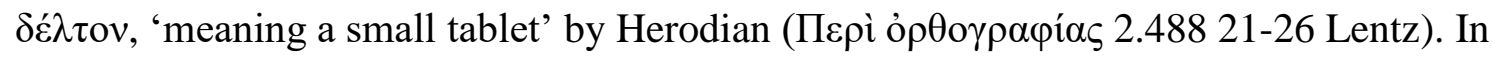
correspondence with that interpretation, Orus supposedly has said:

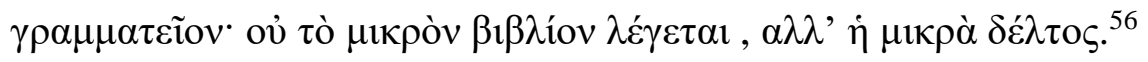

\footnotetext{
55 The locative meaning of 'scribal office' or 'record office' seems to have been taken over by the female derived noun $\gamma \rho \alpha \mu \mu \alpha \tau \varepsilon i ́ \alpha$ in the Roman period, which used to refer to the post of a scribe. For example, when Menches

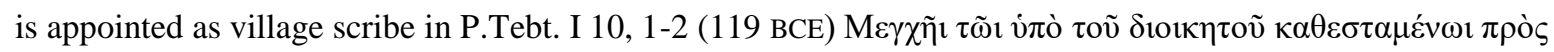

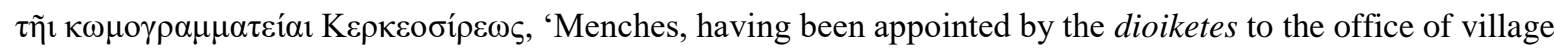

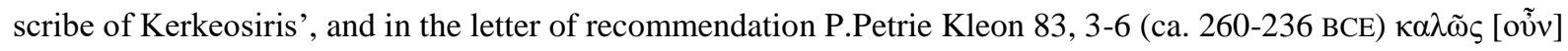

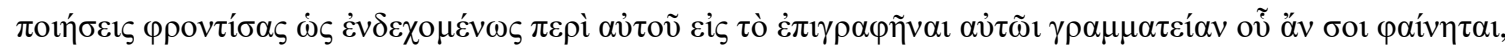
'please, try all that is in your ability to make sure that a scribal post is arranged for him wherever you think fit'. This becomes extended to refer to the physical office itself as well as the taxes in support of a record office (see Wallace 1938, 277-278). Most of the attestations are either spelled with $\langle\varepsilon 1\rangle$ or they are abbreviated, but

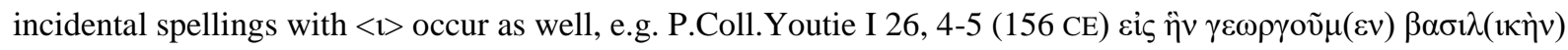

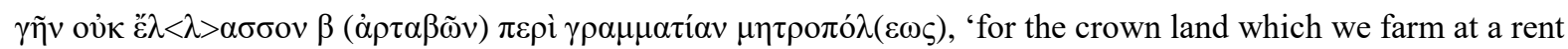
of no less than 2 artabas in the area of the scribal office of the metropolis'. The use of this lexeme spelled with $<\varepsilon l>$ is continued in the Modern Greek $\gamma \rho \alpha \mu \mu \alpha \tau \varepsilon i ́ \alpha$,'secretariat'.

${ }^{56}$ B 58 Alpers. Translation by author.
} 
$\gamma \rho \alpha \mu \mu \alpha \tau \varepsilon i ̃ o v$ does not refer to a small roll, but to a small tablet.

When Pollux (Onom. 4.18 Bethe) discusses various words for the writing tablets used by teachers, he mentions that Herodotus calls a double tablet $\delta \varepsilon \lambda \tau i ́ o v ~ \delta i ́ \pi \tau v \chi o v$ (Hdt. 7.239), the Attic writers $\gamma \rho \alpha \mu \mu \alpha \tau \varepsilon i ̃ o v ~ \delta i ́ \theta v \rho o v$, while Homer (Il. 6.169) has $\pi i ́ v \alpha \kappa \alpha \pi \tau v \kappa \tau \tilde{\omega}$. The noun $\gamma \rho \alpha \mu \mu \alpha \tau \varepsilon i{ }^{\circ} v$ as 'writing tablet' in Attic could indeed be another derivation from the noun $\gamma \rho \alpha \mu \mu \alpha \tau \varepsilon ́ v \varsigma$, 'scribe', but this etymology does not need to exclude other writing materials. ${ }^{57}$ Whereas tablets served as scribal tools for a long time, the precise material on which one writes may not have been an essential part of the meaning of this lexeme throughout this period.

Tablets were used in Egypt as well, but none of the attestations in papyri seems to refer to a writing tablet strictly speaking. One of the attestations of $\gamma \rho \alpha \mu \mu \alpha \tau(\varepsilon) 10 v$ from the Roman period, gives an indication to the type of material that was used:

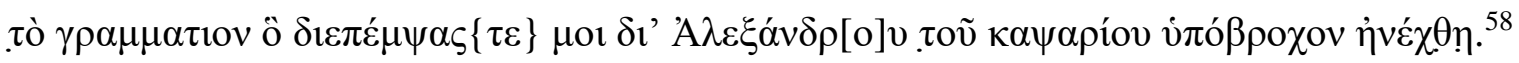

the document which you sent to me through Alexandros the capsarius (i.e. the one who watches the clothes in the baths) was brought wet.

Since the document is argued to have become too wet to read its contents, it must have been written with ink on a more vulnerable type of material, such as papyrus. The word $\gamma \rho \alpha \mu \mu \alpha \tau \varepsilon i ̃ o v$ in the papyri is, therefore, more likely to have referred to 'a written document' of some sort, which could have been written by scribes on various kinds of materials.

\footnotetext{
${ }^{57}$ See also Chantraine 1933, 60.

${ }^{58}$ P.Strasb. IV 260, 1-3 (161 CE). Translation by author.
} 


\subsubsection{Juridical documents}

Soon after the reappearance of $\gamma \rho \alpha \mu \mu \alpha \tau(\varepsilon) 10 v$ in the corpus of papyrus documents, the lexeme seems to have been applied to a more specific type of writing, namely a juridical document. ${ }^{59}$ Around the middle of the second century, the lexeme appears for the first time in one of the juridical clauses of a loan contract, in a phrase added between the execution clause and validity clause:

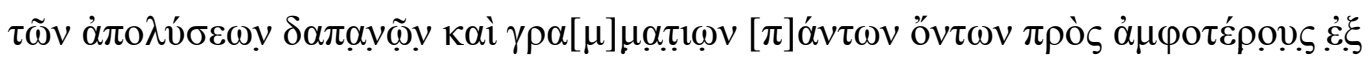
ǐ́ov. ${ }^{60}$

all expenses and documents of discharge are paid by both in equal shares.

By the third century CE, it is also found in the validity clause of contracts, besides the more popular $\chi \varepsilon 1 \rho o ́ \gamma \rho \alpha \varphi \circ v$ 'manuscript, bond', to refer to the document at hand:

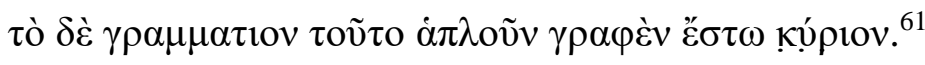

this deed, written as a single copy, shall be valid.

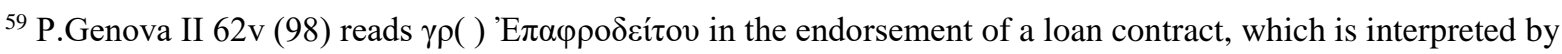
the editor as $\gamma \rho \alpha \mu \mu \alpha \tau(\varepsilon)$ เov 'E $\pi \alpha \varphi \rho \circ \delta \varepsilon i \tau o v$, 'deed of Epaphrodeitos'. If this supplement is correct, this would be earliest attestation of the lexeme in the Roman period and it would immediately firmly connect the use of this lexeme to a juridical context.

${ }^{60}$ SB XIV 11599, 12-17 (155 CE). Translation by author.

${ }^{61}$ SB IV 7358, 16-17 (277-282), see also $B L 7,193$. Translation by author.
} 
The same applies to the endorsement of a contract in SB XIV 12190v (297) as $\gamma \rho \alpha \mu \mu \alpha \tau \varepsilon i ̃ o v$

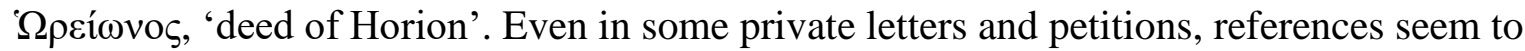
point to the interpretation as contract, e.g. in the petition P.Cair.Isid. 62, 22 (297) $\gamma \rho \alpha \mu \mu \alpha \tau 1 \omega v$ (1. $\gamma \rho \alpha \mu \mu \alpha \tau 10 v) \tau \tilde{\eta} \varsigma \dot{v} \pi \alpha \lambda \lambda \alpha \gamma \tilde{\eta} \varsigma$, 'deed of security'. ${ }^{62}$ This usage of the lexeme is also attested in contemporary lexica. Pollux (Onom. 8.140 Bethe) mentions it in a list of terms referring to

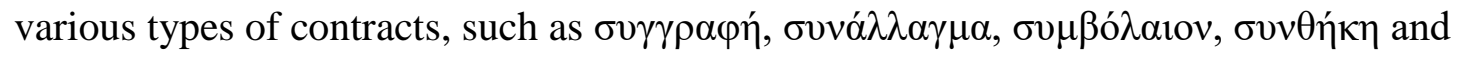

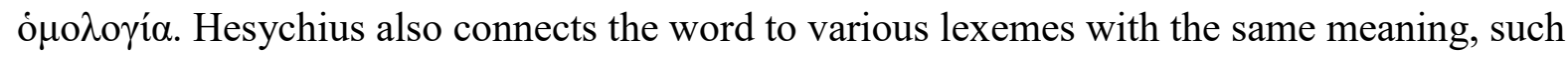

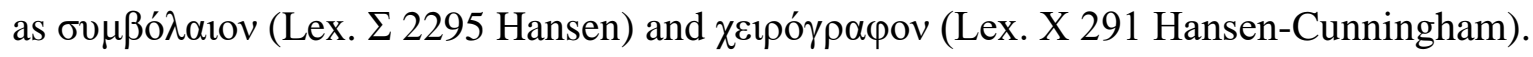
The original meaning referring to writing material and, by metonymic extension to the document itself, very soon seems to have acquired an even more specialized meaning by its almost exclusive use in legal contexts in documentary papyri.

\subsubsection{Spelling variation}

During the third century CE, the lexeme is still only used occasionally and both spellings are found in equal numbers ( 5 times spelled with $\langle 1\rangle$ and 5 times with $\langle\varepsilon \uparrow\rangle$ ), but attestations become increasingly more frequent in papyri from the fourth century onwards. The increased use of the lexeme in juridical contexts seems to coincide with a more consistent spelling. Out of all attestations of the lexeme during the fourth to sixth centuries CE, 189 are written with

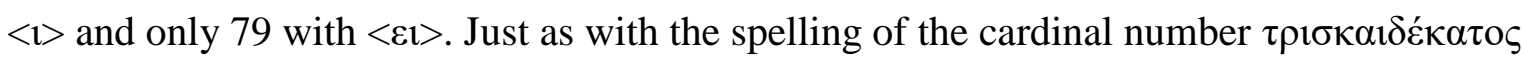
(section 4), however, there are significant geographical differences in spelling during the Byzantine period.

In the Oxyrhynchite nome, the spelling with $<_{1}>$ (45 times) seems to have become the norm. During the later fourth, fifth and sixth centuries, the spelling with $\langle 1\rangle$ is used without

\footnotetext{
${ }^{62}$ Other early attestations in private letters, such as P.Bagnall 12, 2-5 (ca. 115-130 CE) and P.Mil.Vogl. II 76, 1619 (II CE), are less explicit, but they also seem to concern official, perhaps juridical, documents.
} 
exception in the Oxyrhynchite. ${ }^{63}$ In the Hermopolite nome, there is much more variation in the spelling of this lexeme, as both spellings appear in equal quantities (29 times) during the fourth to sixth centuries. Interestingly, the spelling with $<_{1}>$ is mainly found in witness subscriptions (23 out of the 29 attestations) in the Hermopolite, whereas the spelling with $\langle\varepsilon 1\rangle$ also occurs in the parts of a contract commonly written by a professional scribe, such as the execution and validity clauses and the subscriptions by the parties (18 out of the 29). In practice, this means that both spellings may occur in the same document dependent on the person who wrote that part. For example, in BGU XVII 2687 (Hermopolis, early VI), the spelling with $\langle\varepsilon 1\rangle$ is found in the validity clause of the contract and the subscriptions by the party (Aurelius Victor written for him by Aurelius Zacharias from Hermopolis) and the first witness (Flavius Taurinus from Hermopolis), while the second witness (Aurelius Theodosis from Hermopolis) writes $\mu \alpha \rho \tau v \rho \tilde{\omega} \tau \tilde{\omega} \gamma \rho \alpha \mu \mu \alpha \tau i \omega$, 'I witness the deed' (1. 6) spelled with $<1>.{ }^{64}$ Judging from his handwriting, Aurelius Theodosis was clearly able to write, but that does not mean that he followed the local orthographic norms of the professional scribes in the Hermopolite nome.

The situation is more difficult to assess for the seventh century, since more than half of the attestations are abbreviated by this time (41 out of the 70). Especially the scribes in the

\footnotetext{
${ }^{63}$ The spelling $\gamma \rho \alpha \mu \mu \alpha \tau \varepsilon \tilde{i o v}$ is attested in only four texts from the Oxyrhynchite and these attestations all date to the early fourth century. They happen to be attested in other genres than contracts, where there may have been less consistent scribal practices, see P.Oxy. LX 4075, 17, 19 and 21 (daybook, 318), P.Oxy. LIV 3757, 17, 22, and possibly 13 and 19 (proceedings, 325), P.Princ. II 77, 13 (petition, early IV, see BL IX 220) and PSI V 452, 5 and 13 (petition, first half IV, see $B L$ VII, 235).

${ }^{64}$ The spelling $\gamma \rho \alpha \mu \mu \alpha \tau i ́ \omega$ in 1.7 was read by mistake by the editor of $B G U$ XVII 2687: I read $\gamma \rho \alpha \mu \mu \alpha \tau \varepsilon i ́ \omega$ on the digital image. The epsilon has also been overlooked in the edition of $C P R$ IX 3 (V-VI): $\gamma \rho \alpha \mu \alpha \tau \iota$ in 1.4 should be read as $\gamma \rho \alpha \mu \alpha \tau \varepsilon i ́ \omega$ (based on digital image). Variation in spelling by the witnesses is also found in
} BGU XII 2185 (ca. 512), CPR VII 40 (492), P.Gen. IV 190 (522 or 523) and P.Jena II 17 (ca. 515). 
Oxyrhynchite are very consistent: all but two of the attestations are abbreviated. Still, the

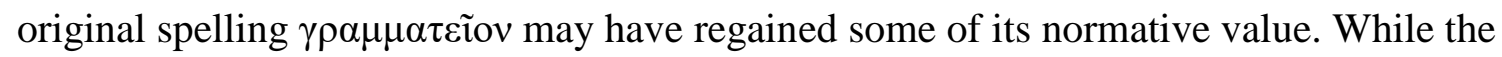
spelling with $<_{1}>$ is still found in the subscription to an acknowledgement of debt in P.Oxy. LXXV 5070, 20 (605-606 or 620-621), the spelling with $\langle\varepsilon 1>$ is attested in the validity clause of an acknowledgement of debt in P.Oxy. LXXII 4930, 21 (614). In the Hermopolite, the spelling with $\langle 1\rangle$ is no longer found at all during the seventh century.

\subsubsection{Orthography and accentuation}

The formalization of the derived noun $\gamma \rho \alpha \mu \mu \alpha \tau(\varepsilon)$ lov to the more specific meaning 'contract' in juridical contexts may have provided the opportunity to spread a different spelling, and perhaps pronunciation, as the norm in certain contexts. Local scribal practices managed to spread the spelling with $\langle 1\rangle$ widely in legal documents between the fourth and the seventh centuries CE. An additional piece of information about the pronunciation in the later period is offered by its spelling as a loanword in Coptic during the seventh and eighth centuries. Both the spellings with $\left\langle 1>\right.$ and $\left\langle\varepsilon \mathrm{l}>\right.$ are found in Coptic, ${ }^{65}$ but the variant spelling rpammatıN

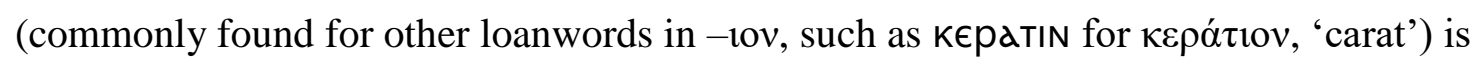
absent. ${ }^{66}$ This makes it likely that the accent was, at least at that time, pronounced on the penultimate syllable rather than on the antepenultimate, preventing the omission of the omicron in the final syllable. This practice is likely to have been applied also to the Hermopolite in earlier periods, where the spelling with $\langle\varepsilon \mathrm{l}\rangle$ always seems to have been the norm. The chronological and geographical variation between $\gamma \rho \alpha \mu \mu \alpha \tau \varepsilon i ̃ o v$ and $\gamma \rho \alpha \mu \mu \alpha \tau i ́ v$

\footnotetext{
${ }^{65}$ See e.g. Förster 2002, 153-154.

${ }^{66}$ I would like to thank Alain Delattre for bringing this to my attention.
} 
could then have been purely orthographic in nature rather than reflecting an actual difference in pronunciation.

The comments by grammarians and lexicographers suggest that the spelling and pronunciation of the words $\gamma \rho \alpha \mu \mu \alpha ́ \tau t o v$ and $\gamma \rho \alpha \mu \mu \alpha \tau \varepsilon \tilde{o} \mathrm{v}$ were considered particularly ambiguous from the Roman period onwards and explanation was needed in order to

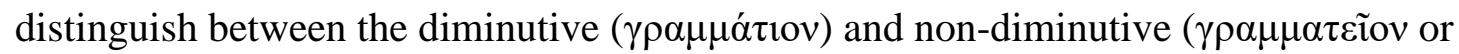
$\gamma \rho \alpha \mu \mu \alpha \tau i$ ov) meaning of the words in written discourse. ${ }^{67}$ This would be necessary in a situation in which the word for 'document', $\gamma \rho \alpha \mu \mu \alpha \tau$ íov, is spelled in the same way as the diminutive $\gamma \rho \alpha \mu \mu \alpha ́ \tau$ เıv by some language users and perhaps confused in pronunciation. This practice may have been behind the consistent spelling with $<1>$ in the Oxyrhynchite districtand possibly other areas - between the fourth and seventh centuries.

\section{Conclusion and discussion}

Modern studies on Greek orthography stand in a long tradition of ancient scholarship with its own criteria to identify 'correct' language use. When contemporary language use diverges from the traditional one, grammarians and lexicographers seem to become increasingly productive to reconstruct and explain the traditional spellings to their contemporary audience. This does not mean that scribes at the time, such as the ones producing the thousands of documents on papyrus in Egypt, always followed their example. Close study of the

\footnotetext{
${ }^{67}$ The twelfth century poet and grammarian Tzetzes teaches the difference between the two lexemes in his

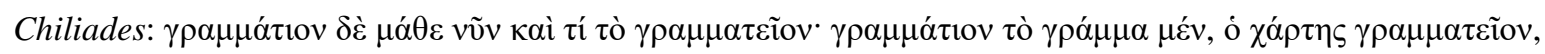

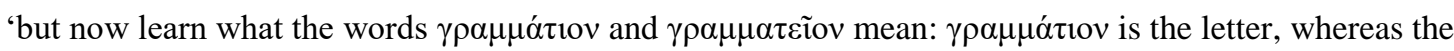
document is $\gamma \rho \alpha \mu \mu \alpha \tau \varepsilon i v^{\prime}$ (Chil. 231, 845-846 Leone). The stress on the difference in accentuation between the diminutive form and the derivative in $-\varepsilon \tilde{o}$ v could help to keep the two forms apart in written and spoken discourse.
} 
attestations in documentary sources may reveal an understanding of the orthography of a lexeme which is different from the one preserved to us in grammatical and lexicographical

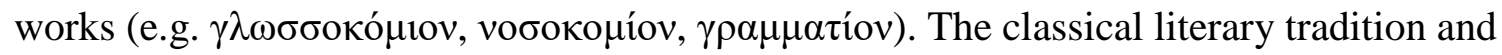
these historical reconstructions, however, continue to influence judgements of spelling by modern editors, even in cases where orthographic variation is in fact very limited or almost

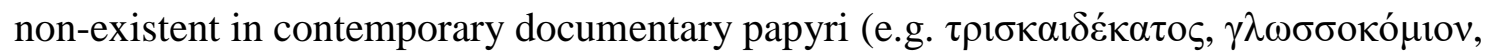
vобоконíov).

This study also revealed some patterns behind the introduction and spread of orthographic variation and change in post-classical Greek. Historical changes in orthographic practices often seem to coincide with other changes in the use of a lexeme, such as a specialization in meaning (e.g. $\kappa \lambda \varepsilon i ́ v \eta, ~ \gamma \rho \alpha \mu \mu \alpha \tau i ́ o v)$ and/or its application in fixed formulae (e.g. $\tau \rho ı \kappa \alpha \iota \delta \varepsilon \kappa \alpha \tau o \varsigma, \gamma \rho \alpha \mu \mu \alpha \tau i ́ o v)$. In this way, the alternative orthography becomes connected to the use of the lexeme in its new context. It is this new package of form and meaning that gets adopted by other scribes and spreads through the community. In Egypt, the historical change from Hellenistic kingdom to Roman rule seems to mark the innovation and spread of these

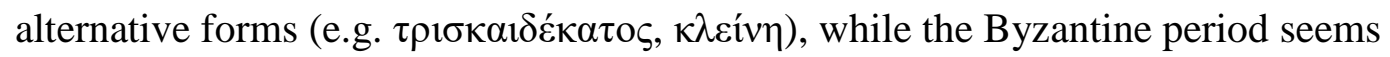
characterized by more regional scribal practices (e.g. $\tau \rho(\varepsilon) 1 \sigma \kappa \alpha \iota \delta \varepsilon ́ \kappa \alpha \tau o \zeta, \gamma \rho \alpha \mu \mu \alpha \tau(\varepsilon)$ íov). The cases of variation and change discussed in this paper advance beyond idiolects. Each of the new orthographies becomes part of standard practice in part of Egypt during several centuries. In the history of the Greek language, however, most of them may be referred to as temporary changes. When a specific tradition or context of use was discontinued, new orthographic norms could be re-established at a later point in time.

What, then, constitutes standard orthography? Can we define the standard by looking at how many people actually used it, how skilled we think they were or for how long a form has been in use? Lexemes attested in documentary sources often exhibit some degree of 
orthographic variation. Almost all orthographic norms have attested exceptions, but that should not distract the scholar from observing the general tendencies. Close study may reveal some patterns of use, but not always a definite change accounting for the spelling in postclassical Greek at a larger scale. It requires a reasonable amount of evidence and thorough comparison of the attestations to deduce these orthographic changes in post-classical Greek, but this kind of analysis could change our ideas about the standard spelling in this period and rectify our judgements about the scribes who actually applied contemporary norms consistently. Even though the editorial practice to regularize alternative spellings may have been helpful to identify possible candidates for orthographic change in this study, I hope to have shown that the regularization of spelling variation in historical periods is a much more complex undertaking than often assumed. ${ }^{68}$

\title{
Bibliography
}

Papyri are cited according to the Checklist of Editions of Greek, Latin, Demotic, and Coptic Papyri, Ostraca, and Tablets, see www.papyri.info/docs/checklist

\author{
$B L=$ Preisigke, F., et al. (1922-2017), Berichtigungsliste der Griechischen Papyrusurkunden \\ aus Ägypten, Vol. I-XIII. Leiden.
}

\footnotetext{
${ }^{68}$ Parts of this study have been presented at A Koine Greek Colloquium (19 May 2017, Macquarie University), the OIKOS research day (18 November 2017, Katwijk) and the conference 'The Language of Law in Ancient Documents: Transformation and Continuity of Legal Formulae in Diachronic and Geographic Perspective' (2224 November 2018, Leiden University). I would like to thank participants from these audiences for their suggestions and Anastasia Maravela and two anonymous reviewers for their useful comments to an earlier version of this article. My research was funded by Research Foundation - Flanders (FWO) and The Research Council of Norway (NFR).
} 
$D G E=$ Adrados, F.R., Gangutia, E., Facal, J.L., Serrano, C., and Arboledas, A. (1989-).

Diccionario griego-español. Madrid. First part available online at http://dge.cchs.csic.es.

LSJ = Liddell, H.G., and Scott, R. 1996. A Greek-English Lexicon. Oxford.

$P N=$ Papyrological Navigator,$\underline{\text { www.papyri.info }}$

$T M=$ Trismegistos Portal, $\underline{\text { www.trismegistos.org }}$

Beekes, R. (2010). Etymological Dictionary of Greek. Leiden/Boston.

Chantraine, P. (1933) La formation des nom en grec ancien. Paris.

Chantraine, P. (1968-1980). Dictionnaire étymologique de la langue grecque. Paris.

Depauw, M., and Stolk, J.V. (2015). Linguistic Variation in Greek Papyri. Towards a New Tool for Quantitative Study. GRBS 55, pp. 196-220.

Evans, T. (2010). Standard Koine Greek in Third Century BC Papyri. In: T. Gagos, ed., Proceedings of the Twenty-Fifth International Congress of Papyrology, Ann Arbor, pp. 197-206.

Förster, H. (2002). Wörterbuch der griechischen Wörter in den koptischen dokumentarischen Texten. Berlin/New York.

Gignac, F.T. (1976). A Grammar of the Greek Papyri of the Roman and Byzantine Periods, Vol. 1: Phonology. Milan.

Gignac, F.T. (1981). A Grammar of the Greek Papyri of the Roman and Byzantine Periods, Vol. 2: Morphology. Milan.

Horrocks, G. (2010). Greek. A History of the Language and its Speakers. $2^{\text {nd }}$ ed. Malden, MA/Chichester.

Lampe, G.W.H. (1961). A Patristic Greek Lexicon. Oxford.

Leiwo, M. (2003). Scribes and Language Variation. In: L. Pietilä-Castrén and M. Vesterinen, eds., Grapta Poikila I, Athens, pp. 1-11. 
Maravela, A. (2018). Medical Micro-language in the Greek Papyri. In: N. Reggiani and F. Bertonazzi, eds., Parlare la medicina. Fra lingue e culture, nello spazio e nel tempo, Florence, pp. 12-29.

Mayser, E., and Schmoll, H. (1970). Grammatik der griechischen Papyri aus der Ptolemäerzeit, Vol. 1; Part 1. Berlin.

Miller, T.S. (1985). The Birth of the Hospital in the Byzantine Empire. Baltimore/London. van Minnen, P. (1995). Medical Care in Late Antiquity. In: Ph.J. van Eijk, H.F.J. Horstmanshoff, and P.H. Schrijvers, eds., Ancient Medicine in Its Socio-cultural Context, Amsterdam/Atlanta, pp. 153-169.

Monserrat, D. (1992). The Kline of Anubis. The Journal of Egyptian Archaeology 78, pp. 301-307.

Montenari, F. (2015). The Brill Dictionary of Ancient Greek. Leiden/Boston.

Moulton, J.H. (1929). A Grammar of New Testament Greek. Vol. II: Accidence and WordFormation Edinburgh.

Palmer, L.R. (1945). A Grammar of the Post-Ptolemaic Papyri. London.

Perrone, S. (2011). Back to the Backstage. The Papyrus P.Berol. 13927. Trends in Classics 3, pp. 126-153.

Preisigke, F. (1925). Wörterbuch der griechischen Papyrusurkunden, Vol. 1-2. Berlin.

Preisigke, F. (1931). Wörterbuch der griechischen Papyrusurkunden, Vol. 3: Besondere Wörterliste. Berlin.

Rutkowska, H., and Rössler, P. (2012). Orthographic Variables. In: J.M. Hernández-Campoy, and J.C. Conde-Silvestre, eds., The Handbook of Historical Sociolinguistics, Malden, MA/Chichester, pp. 213-236.

Siebenborn, E. (1976). Die Lehre von der Sprachrichtigkeit und ihren Kriterien. Studien zur antiken normativen Grammatik. Amsterdam. 
Sophocles, E.A. (1914). Greek Lexicon of the Roman and Byzantine Periods. Cambridge.

Stolk, J.V. (2015). Scribal and Phraseological Variation in Legal Formulas. The Adjectival Participle of íxá $\chi \omega$ + Dative or Genitive Pronoun. JJP 45, pp. 255-290.

Stolk, J.V. (2018). Encoding Linguistic Variation in Greek Documentary Papyri. The Past, Present and Future of Editorial Regularization. In: N. Reggiani, ed., Digital Papyrology II. Case Studies on the Digital Edition of Ancient Greek Papyri, Berlin/Boston, pp. 119-137.

Teodorsson, S.-T. (1977). The Phonology of Ptolemaic Koine. Göteborg.

Valente, S. (2015). Orthography. In: F. Montanari, S. Matthaios, and A. Rengakos, eds., Brill's Companion to Ancient Greek Scholarship. Leiden/Boston, pp. 949-977.

Vierros, M. (2012). Phraseological Variation in the Agoranomic Contracts from Pathyris. In: M. Leiwo, H. Halla-Aho, and M. Vierros, eds., Variation and Change in Greek and Latin, Helsinki, pp. 43-56.

Wallace, S.L. (1938). Taxation in Egypt from Augustus to Diocletian. New York. 